\title{
Kompetensi Pengkajian Primary Survey dengan Pendekatan Metode Journal Sharing Of Critical Care (JSCC) pada Mahasiswa Profesi Ners
}

\author{
Heru Suwardianto $^{1 *}$, Vitaria Wahyu Astuti \\ ${ }^{1,2}$ STIKES RS. Baptis Kediri \\ *Email: herusuwardianto@gmail.com
}

\begin{abstract}
Background: Primary Survey is important to be achieved by nursing students in carrying out early detection of critical patient conditions. Innovation of learning methods is a challenge for teachers to improve the quality of student competencies. The research objective is the Primary Survey critical nursing competency with the method of journal sharing of critical care (JSCC) approach to nursing professional students. Methods: The research design is descriptive analytic. The study population was all professional students in 2020. The research sample was professional students in 2020 using total sampling. The size of the study sample was 39 respondents with the inclusion of students who had completed the medical surgical nursing profession and followed the critical nursing profession to completion. Primary Survey independent variable. Data were collected using a questionnaire and analyzed using data frequency distribution. Results: Showed that the most respondents had primary survey critical nursing competency values obtained good value on the airway assessment of 53.8 respondents, breathing assessment of $56.4 \%$ of respondents, Circulation assessment of $61.5 \%$ of respondents, Disability assessment of $56.4 \%$ of respondents, and Exprosure Assessment by 59\% of respondents. Conclusion: The implementation of learning methods for journal sharing of critical care has a positive impact on student competencies to carry out primary survey assessments and produce good student competencies. It is not only the learning process that supports a competency but also the ability of students to follow the learning method.
\end{abstract}

Keywords: competence, critical care, journal sharing, primary survey

\section{PENDAHULUAN}

Kompetensi keperawatan kritis merupakan salah satu pencapaian pada mahasiswa profesi keperawatan di Indonesia. Pencapaian kompetensi dilakukan melalui berbagai metode pembelajaran sehingga dapat melihat hasil kompetensi yang diharapkan. Kompetensi keperawatan melalui proses analisis konsep hingga hasil. Berbagai elemen kompetensi dilakukan penilaian untuk melihat hasil dari proses belajar. Kompetensi keperawatan menerapkan keterampilan disemua domain dalam peran praktik bagi mahasiswa. Kompetensi dibangun yang berfokus pada hasil atau kompetensi tertentu, dan juga perlunya sarana penunjang untuk meningkatkan tingkat kompetensi, akuntabilitas pelajar, pembelajaran berbasis praktik, penilaian diri, dan individual pengalaman belajar (Donna \& Tilley, 2008).

Dampak dari proses pembelajaran pada mahasiswa keperawatan adalah suatu perbedaan yang signifikan dalam konstruk kompetensi budaya (Kohlbry, 2016). Nilai potensial dari standar kompetensi keperawatan diperlukan untuk mengembangkan dan menguji standar yang kuat yang dapat mengkomunikasikan keterampilan dan pengetahuan yang dibutuhkan perawat pada setiap tatanan pelayanan kesehatan (Halcomb \& Steohens, 2016). Lingkungan belajar di rumah sakit ataupun di kampus dapat meningkatkan dan menjamin kompetensi dengan melibatkan pembelajar dalam penilaian dan akuntabilitas, memberikan peluang pembelajaran kepada mahasiswa 
dengan berbasis praktik, dan individualisasi pengalaman belajar mahasiswa di lahan praktik. Pencapaian kompetensi pada mahasiswa profesi keperawatan kritis perlu terus dikembangkan dan terus diberi masukan terkait hambatan dan tantangannya.

Perawat di Indonesia pada tahun 2019 mencapai 345.508 perawat, pulau Jawa memiliki jumlah perawat terbanyak. Penyebaran perawat di Provinsi Jawa Timur berjumlah 48.164 perawat. Provinsi Jawa Tengah berjumlah 45.107. Provinsi Jawa Barat berjumlah 35.747 perawat, dan di Jakarta berjumlah 26.950 perawat. Penyebaran perawat tidak lebih banyak di Sulawesi Barat ada 1.550 perawat, di Kalimantan Utara ada 1.587 perawat, dan Maluku Utara ada 2.062 perawat.

Terdapat $>600.000$ tenaga perawat merupakan tenaga kesehatan terbesar yang mencapai $49 \%$ dari semua tenaga kesehatan yang telah ada (296.876 perawat). Data BPPSDMK pada Desember 2016 total perawat di Jawa timur mencapai 33.377 perawat (Kemenkes, 2017). Data lain menunjukkan bahwa rasio perawat terhadap seratus ribu populasi di Indonesia didapatkan pada tahun 2014 yaitu sembilan puluh empat perawat per seratus ribu populasi dan diperkirakan pada tahun 2015-2019 sebesar 180 perawat per 100.000 penduduk (Kemenkes, 2017). Klasifikasi Perawat yang telah menempuh jenjang profesi sekitar 10,84\% pada tahun 2017. Kompetensi keperawatan dibuktikan dengan adanya tanda registrasi dari Majelis Tenaga Kesehatan Indonesia dan pada tahun 2016 telah diterbitkan 219.654 perawat yang memiliki STR dengan proporsi penerbitan STR sebesar 41,8\% (Kemenkes, 2017).
Kompetensi keperawatan kritis pada mahasiswa profesi merupakan salah satu tuntutan luas dalam mencapainya dan memerlukan kerja sama tim kesehatan yang tinggi, telah memunculkan banyak inisiatif metode pembelajaran dalam pendidikan dan pencapaian kompetensinya. Kompetensi keperawatan kritis pada mahasiswa profesi bertujuan untuk membangun kompetensi tim. Sebagian besar upaya telah dilakukan dan difokuskan pada metode konvensional dan biasanya jarang menggunakan metode tim interprofessional, apalagi menggunakan jurnal atau hasil penelitian sebagai bahan dalam asuhan keperawatan kritis oleh mahasiswa profesi. Aplikasi hasil penelitian seperti jurnal perlu dicoba dalam pembelajaran pada mahasiswa profesi keperawatan, karena didalamnya terdapat informasi terkini dalam asuhan keperawatan. Jika mahasiswa tidak terpapar oleh jurnal atau hasil penelitian dalam asuhan keperawatan maka akan sangat sulit profesi keperawatan mejadi semakin baik dalam hal sharing ilmu pengetahuan kepada sejawat atau tim keperawatan kritis (Barton \& Bruce, 2018). Manajemen pasien yang sakit kritis merupakan tantangan tersendiri dalam pencapaian kompetensi oleh mahasiswa keperawatan. Prevalensi penyakit komorbiditas yang tinggi menyebabkan jumlah pasien kritis di rumah sakit cukup banyak (Kaldan et al., 2019). Kurikulum dalam profesi keperawatan mudah beradaptasi dan dapat digunakan pada unit perawatan intensif dan dapat terus disempurnakan dengan pendekatan hasil penelitian (Kopf et al., 2018).

Kompetensi mahasiswa keperawatan mencakup semua kemampuan inti yang diperlukan untuk memenuhi peran mahasiswa menjadi 
seorang perawat (Fukada, 2018). Sangatlah penting penjelasan dari mendefinisikan kompetensi keperawatan untuk membangun landasan bagi kurikulum pendidikan keperawatan di Indonesia dalam menyiapkan dan memberikan strategi pembelajaran yang spesifik dengan mengaplikasikan hasil penelitian didalamnya misalnya seperti penggunaan jurnal. Konsep seputar metode pemenuhan kompetensi keperawatan penting untuk meningkatkan kualitas keperawatan salah satunya dengan Journal Sharing Critical Care (JSCC). Tantangan tetap ada dalam menetapkan kompetensi yang ada atau bahwa definisi dan struktur untuk kompetensi keperawatan bagi mahasiswa. JSCC memberikan pengalaman mahasiswa dalam menganalisis jurnal dan selanjutnya digunakan dalam melakukan asuhan keperawatan kepada pasien. Tingkat kompetensi yang diperlukan untuk profesional keperawatan sangatlah bervariasi dan ilmu terkini terkait asuhan keperawatan diperlukan oleh mahasiswa. Tujuan penelitian ini adalah untuk mengetahui kompetensi pengkajian primary survey dengan pendekatan metode Journal Sharing Of Critical Care (JSCC) pada mahasiswa profesi ners.

\section{METODE PENELITIAN}

Peneliti menggunakan metode penelitian analitik deskriptif. Populasi penelitian adalah semua mahasiswa profesi ners di STIKES RS Baptis Kediri. Sampel penelitian adalah mahasiswa profesi ners di STIKES RS Baptis Kediri dengan menggunakan total sampling, dengan cara melakukan sampling yang menggunakan seluruh populasi sebagai responden penelitian. Variabel independen penelitian adalah metode pembelajaran
Journal Sharing of Critical Care (JSCC). Variabel dependen penelitian ini adalah primary survey berupa pengkajian airway, breathing, circulation, disability, exprosure. Alur penelitian yaitu mahasiswa dilakukan penjelasan terkait metode Journal Sharing Of Critical Care (JSCC) menggunakan aplikasi Edlink. Selanjutnya mahasiswa diberikan format pengerjaan tugas untuk menganalisis jurnal atau hasil penelitian yang berfokus pada asuhan keperawatan kritis. Tahap ke 2, mahasiswa membuat suatu asuhan keperawatan terintegrasi dengan intervensi atau alat ukur berdasarkan jurnal atau hasil penelitian yang telah dilakukan analisis sebelumnya. Peneliti melakukan pengukuran hasil dari penilaian primary survey. Penelitian telah mendapatkan etichal clearence dari STIKES RS Baptis Kediri. Penelitian pada bulan Maret sampai dengan April 2020 menggunakan kuesioner berbasis Aplikasi Eddlink dan Google Form. Hasil penelitian dilakukan tabulasi dan pengkodingan selanjutnya dilakukan analisis distribusi frekuensi data.

\section{HASIL PENELITIAN}

Hasil penelitian didapatkan 39 responden dengan komposisi yang berjenis kelamin terdapat 7 responden $(17,9 \%)$, responden berjenis kelamin perempuan ada tiga puluh dua responden $(82,1 \%)$, usia responden paling banyak berusia 27 tahun (69,2\%), dengan kepeminatan materi keperawatan kritis yaitu sistem kardiovaskular sebanyak 22 responden $(56,4 \%)$. Hasil penelitian menunjukkan bahwa paling banyak mahasiswa keperawatan lebih memahami permasalahan medis gagal napas dan penyakit jantung coroner dari pada masalah medis yang lain. Mahasiswa 
memahami diagnosa medis tersebut dimaknai bahwa mahasiswa memahami etiologi masalah medis, manifestasi klinis, patofisiologi, diagnostik klinis, tatalaksana medis, pengkajian asuhan keperawatan, menentukan diagnosa masalah berdasarkan primary assessment, menyusun intervensi dan mengembangkan berdasarkan hasil penelitian atau bukti, dan melakukan evaluasi reasoning process dan patient safety.

Tabel 1. Evaluasi Kompetensi Keperawatan Kritis Primary Survey

\begin{tabular}{|c|c|c|c|c|c|c|c|c|c|}
\hline \multirow{3}{*}{ Primary Survey } & \multicolumn{8}{|c|}{ Tingkat Kompetensi Mahasiswa } & \multirow{3}{*}{ Pearson } \\
\hline & \multicolumn{2}{|c|}{ Kurang } & \multicolumn{2}{|c|}{ Cukup } & \multicolumn{2}{|c|}{ Baik } & \multicolumn{2}{|c|}{ Sangat baik } & \\
\hline & $\sum$ & $\%$ & $\sum$ & $\%$ & $\sum$ & $\%$ & $\sum$ & $\%$ & \\
\hline Airway & 2 & 5,1 & 10 & 25,6 & 21 & 53,8 & 6 & 15,6 & 0,038 \\
\hline Breathing & 2 & 5,1 & 9 & 23,1 & 22 & 56,4 & 6 & 15,4 & 0,052 \\
\hline Circulation & 2 & 5,1 & 8 & 20,5 & 24 & 61,5 & 5 & 12,8 & 0,029 \\
\hline Disability & 2 & 5,1 & 10 & 25,6 & 22 & 56,4 & 5 & 12,8 & 0,107 \\
\hline Exposure & 3 & 7,7 & 8 & 23,1 & 23 & 59 & 5 & 12,8 & 0,023 \\
\hline
\end{tabular}

bahwa Evaluasi kompetensi keperawatan kardiovaskular. Paling banyak mahasiswa kritis pada primary assessment keperawatan lebih memahami menunjukan paling banyak mahasiswa permasalahan medis gagal napas dan mendapatkan penilaian yang baik. Hasil Penyakit jantung coroner dari pada menunjukkan ada lebih dari 50 persen masalah medis yang lain. Hal ini mahasiswa mendapatkan penilaian baik. menunjukkan bahwa mahasiswa lebih Evaluasi profesionalitas mahasiswa tertarik pada kasus kardiovaskular yang didapatkan paling banyak mendapatkan kemungkinan cukup banyak terjadi di nilai yang baik. Kompetensi asuhan keperawatan kritis mahasiswa mayoritas mendapatkan nilai yang baik. Kemampuan clinical reasoning pada mahasiswa didapatkan mayoritas mendapatkan nilai yang baik. Kemampuan dalam hal patient safety pada mahasiswa didapatkan paling banyak memiliki nilai baik. Exam score critical care memiliki hubungan erat terhadap nilai primary assessment (Airway, Breathing, Circulation, dan Exposure), kompetensi asuhan keperawatan dan clinical.

\section{PEMBAHASAN}

Berdasarkan hasil penelitian memperlihatkan bahwa mahasiswa paling banyak memiliki kepeminatan keperawatan kritis di ICU.

Kasus-kasus pasien dengan gagal napas juga sangat banyak dan memperlukan asuhan keperawatan yang spesifik dan menjadi tantangan mahasiswa untuk melaksanakan asuhan keperawatan mengkomparasikan dengan intervensi atau alat berdasarkan jurnal penelitian atau berdasarkan bukti seperti sleep hygiene, VAP, dan lainnya (Suwardianto, 2018; Suwardianto \& Sari, 2020, 2019). Implementasi JSCC mahasiswa diminta untuk mengkaji kasus yang banyak terjadi dan menjadi kepeminatan mahasiswa yang dalam hal ini adalah pasien gagal napas atau pasien dengan gangguan kardiovaskular. Hasil penelitian juga mahasiswa dapat melakukan analisis jurnal menggunakan PICO (population, 
intervention, comparation, dan outcome). Hasil proses pembelajaran dengan pendekatan JSCC mahasiswa banyak menggunakan Evidence base practice seperti bundle of Ventilator mechanic, Bundle of VAP (ventilation associate pneumonia).

Hasil penelitian didapatkan bahwa mahasiswa mampu memahami diagnosa medis untuk mencari keterkaitan asuhan keperawatan. Pemahaman tersebut akan mempermudah mahasiswa dalam mencari jurnal atau hasil penelitian yang dapat diaplikasikan dan dikomparasikan kedalam asuhan keperawatan. Mahasiwa melakukan analisa PICO terhadap jurnal apakah sudah sesuai dengan asuhan keperawatan dan nursing care plan yang dituliskan. Mahasiswa mampu menjelaskan kasus sesuai dengan kondisi pasien. Mahasiswa mampu mencari masalah utama berdasarkan primary assessment yang ada dalam kasus. tersebut dimaknai bahwa mahasiswa memahami etiologi masalah medis, manifestasi klinis, patofisiologi, diagnostik klinis, tatalaksana medis, pengkajian asuhan keperawatan, menentukan diagnosa masalah berdasarkan primary assessment, menyusun intervensi dan mengembangkan berdasarkan hasil penelitian atau bukti, dan melakukan evaluasi.

Pemahaman keperawatan kritis penting bagi mahasiswa untuk menyiapkan diri mereka menghadapi praktik nyata di rumah sakit (Suwardianto \& Richard, 2017; Suwardianto \& Selvia, 2015). Mempersiapkan diri dengan berbagai metode pembelajaran salah satunya dengan JSCC sangatlah baik untuk dicoba. Berdasarkan hasil penelitian menunjukkan bahwa dalam evaluasi kompetensi keperawataan kritis pada mahasiswa profesi didapatkan mayoritas mendapatkan penilaian yang baik pada beberapa aspek diantaranya aspek penilaian pemahaman primary Assessment, profesionalitas, kompetensi Asuhan keperawatan kritis, Clinical Reasoning, patient safety, dan Exam Score Critical Care. Proses pembelajaran JSCC disimpulkan efektif untuk dilakukan dan mahasiswa dapat merasakan hal baru dalam proses pembelajaran. Mahasiswa pada awalnya mengalami kesulitan karena adanya tantangan baru dan belum pernah melakukan dalam jadwal yang padat dan cukup banyak yang dianalisa. Mahasiswa mendapatkan pengalaman baru dan berusaha untuk mengerjakan sebaikbaiknya sehingga dapat menyelesaikan asuhan keperawatan kritis dengan baik (Suwardianto, 2014, 2018; Suwardianto \& Rimawati, 2018; Yusiana \& Suwardianto, 2018). Banyak intervensi ataupun alat ukur yang dapat digunakan untuk asuhan keperawatan kritis yang bermanfaat bagi pasien.

Kompetensi perawat kritis yang disiapkan melalui metode pembelajaran akan menciptakan pengalaman perawat merawat pasien dengan perawatan intensif. Penemuan masalah dan proses mencari solusi pada mahasiswa melalui jurnal atau hasil penelitian sangat dirasakan manfaatnya dan mahasiswa mendapatkan solusi terbaik dalam mengerjakan asuhan keperawatan kritis. Mahasiswa akan mampu melewati proses pelaporan asuhan keperawatan melalui sharing journal of critical care (JSCC) yang telah dikerjakan sebelumnya. Hal tersebut sangat menemukan cara untuk membantu melewati proses Pendidikan profesi mereka. Mahasiswa akan memperoleh pengalaman yang berarti mulai dari mengetahui keluhan hingga keamanan pasien, sesuai terlihat dari hasil 
penelitian sebelumya ada yang menyatakan terdapat dalam pengalaman pemahaman perawat akan ditemukan maslaah kelelahan, gambaran status mental, keamanan pasien (Sánchez Expósito et al., 2018).

Mahasiswa diharapkan dapat berkolaborasi antar profesional dalam meningkatkan perawatan pasien di unit perawatan intensif (ICU) nantinya. Kerangka kerja kompetensi pada mahasiswa akan terus meningkatkan kualitasnya dalam kompetensi interprofessional. Hal tersebut merupakan upaya yang digunakan untuk mendukung pengembangan sikap, pengetahuan, keterampilan, dan perilaku yang diperlukan untuk pendekatan interprofesional dalam perawatan. Mahasiswa keperawatan dalam pengaplikasian jurnal perlu terus ditingkatkan untuk mendukung kualitas pembelajaran selanjutnya. Profesi keperawatan perlu terus ditingkatkan dan dikembangkan melalui aplikasi jurnal dapat menggunakan metode JSCC untuk menunjukkan komunikasi antarprofesional, pemahaman peran, dan kerja tim, yang mendukung sejumlah kompetensi kolaboratif utama. Hal ini sesuai dengan penelitian bahwa kompetensi interprofesional dapat memainkan peran penting dalam mempromosikan pengetahuan, sikap, keterampilan, dan perilaku yang diperlukan. Kompetensi yang mempromosikan kolaborasi antar profesional tergantung pada serangkaian faktor kontekstual yang memungkinkan (atau menghambat) individu untuk benarbenar membuat kompetensi ini (Deacon et al., 2017; Goldman et al., 2018). Hasil penelitian menunjukkan juga bahwa kompetensi penting yang dimiliki calon perawat adalah prognostikasi, mediasi konflik, komunikasi empatik, dan aspek perawatan yang berpusat pada keluarga, dan aspek kompetensi yang paling penting perawatan yang berpusat pada keluarga (Schram et al., 2016). Kami sebagai peneliti berterimakasih kepada Kemenristek DIKTI dalam Hibah penelitian 2019 pelaksanaan penelitian 2020. Kami juga tidak lupa untuk berterima kasih kepada para responden dan semua yang terlibat didalamnya.

\section{KESIMPULAN DAN SARAN}

Hasil penelitian menunjukkan bahwa evaluasi kompetensi keperawatan kritis pada primary asessment menunjukan sebagian besar mahasiswa mendapatkan penilaian yang baik. Evaluasi profesionalitas mahasiswa didapatkan sebagian besar mendapatkan nilai yang baik. Kompetensi asuhan keperawatan kritis mahasiswa mayoritas mendapatkan nilai yang baik. Kemampuan clinical reasoning pada mahasiswa didapatkan mayoritas mendapatkan nilai yang baik.

Kemampuan dalam hal patient safety pada mahasiswa didapatkan paling banyak memiliki nilai baik. Exam score critical care memiliki hubungan erat terhadap nilai primary assessment (airway, breathing, circulation, dan exposure), kompetensi asuhan keperawatan, dan clinical. Hasil penelitian ini dapat sebagai rekomendasi dalam pelaksanaan metode pembelajaran kepada mahasiswa profesi untuk mendukung metode pembelajaran yang lain ditatanan klinis.

\section{DAFTAR RUJUKAN}

Barton, G., \& Bruce, A. (2018). Teaching nurses teamwork: Integrative review 
of competency-based team training in nursing education. Nurse Education in Practice, 32, 129-137.

Deacon, K. S., Baldwin, A., Donnelly, K. A., Freeman, P., Himsworth, A. P., Kinoulty, S. M., Kynaston, M., Platten, J., Price, A. M., Rumsby, N., \& Witton, N. (2017). The National Competency Framework for Registered Nurses in Adult Critical Care: An overview. Journal of the Intensive Care Society, 18(2), 149-156.

https://doi.org/10.1177/1751143717 691985

Donna, \& Tilley, S. (2008). Competency in Nursing: A Concept Analysis. The Journal of Continuing Education in Nursing, 39(2), 58-64. https://doi.org/https://doi.org/10.392 8/00220124-20080201-12

Fukada, M. (2018). Nursing Competency: Definition, Structure and Development. Yonago Acta Medica, 61(1), 001-007. https://doi.org/https://doi.org/10.331 60/yam.2018.03.001

Goldman, J., Kitto, S., \& Reeves, S. (2018). Examining the implementation of collaborative competencies in a critical care setting: Key challenges for enacting competency-based education. Journal of Interprofessional Care, 32(4), 407-415. https://doi.org/10.1080/13561820.20 17.1401987

Halcomb, E., \& Steohens, M. (2016). Nursing competency standards in primary health care: an integrative review. Journal of Clinical Nursing, 25, 9-10. https://doi.org/https://doi.org/10.111 1/jocn.13224

Kaldan, G., Nordentoft, S., Herling, S. F., Larsen, A., Thomsen, T., \& Egerod, I. (2019). Evidence characterising skills, competencies and policies in advanced practice critical care nursing in Europe: a scoping review protocol. BMJ Open, 9(9), e031504.https://doi.org/10.1136/bmj open-2019-031504

Kemenkes. (2017). Pusat Data dan Informasi Kementerian Kesehatan RI: Situasi Tenaga Keperawatan.

Kohlbry, P. W. (2016). The Impact of International Service-Learning on Nursing Students' Cultural Competency. Journal of Nursing Scholarship, 48(3). https://doi.org/https://doi.org/10.111 1/jnu.12209

Kopf, R. S., Watts, P. I., Meyer, E. S., \& Moss, J. A. (2018). A CompetencyBased Curriculum for Critical Care Nurse Practitioners' Transition to Practice. American Journal of Critical Care, 27(5), 398-406. https://doi.org/10.4037/ajcc2018101

Sánchez Expósito, J., Leal Costa, C., Díaz Agea, J. L., Carrillo Izquierdo, M. D., \& Jiménez Rodríguez, D. (2018). Ensuring relational competency in critical care: Importance of nursing students' communication skills. Intensive and Critical Care Nursing, 44, 85-91. 
https://doi.org/https://doi.org/10.101 6/j.iccn.2017.08.010

Schram, A. W., Hougham, G. W., Meltzer, D. O., \& Ruhnke, G. W. (2016). Palliative Care in Critical Care Settings: A Systematic Review of Communication-Based Competencies Essential for Patient and Family Satisfaction. American Journal of Hospice and Palliative Medicine $\AA, \quad 34(9), \quad 887-$ 895.https://doi.org/10.1177/1049909 116667071

Suwardianto, H. (2014). The effectiveness of deep breathing and slow stroke back massage to decrease the blood pressure on a patient with hypertension. Indonesian Nursing Journal of Education and Clinic (INJEC), 1(1), 1-12.

Suwardianto, H. (2018). Level Of Perception Emergency Skills In Youth Red Cross. Journal Of Nursing Practice, 2(1), 17-24.

Suwardianto, H., \& Richard, S. D. (2017). Asuhan Kegawatdaruratan Keperawatan Penatalaksanaan Kegawatdaruratan. Media Nusantara.

Suwardianto, H., \& Rimawati. (2018). Explicit Instruction Model (EIM): Daily Training Emergencies Preparedness (DTEP) Toward Skills of Participants the Youth Red Cross. Conferences, The 2nd Joint International, 2(2), 403-410.
Suwardianto, H., \& Sari, D. (2020). Environmental Factors of Sleep Hygiene That Influence The Level of Pain on Criticall ill Patients in Intensive Care Unit. STRADA Jurnal Ilmiah Kesehatan, 9(1 SEArticles).https://doi.org/10.30994/sji k.v9i1.266

Suwardianto, H., \& Sari, D. A. K. W. (2019). Pain Level in Critical Patients With Sleep Hygiene Care In Intensive Care Unit. Journal of Nursing Practice, $3(1 \quad$ SEArticles).https://doi.org/10.30994/jn p.v3i1.61

Suwardianto, H., \& Selvia, D. (2015). Buku Ajar Keperawatan Kegawatdaruratan (Perspektif, Konsep, Prinsip, dan Penatalaksanaan

Kegawatdaruratan). PT. Revka Petra Media.

Yusiana, M. A., \& Suwardianto, H. (2018). The Effectiveness Of Deep Breathing And Slow Stroke Back Massage To Decrease The Blood Pressure On A Patient With Hypertension. Indonesian Nursing Journal Of Education And Clinic (INJEC), 1(1), 31-39. 